\title{
Salivary Selenium and Glutathione Peroxidase among Group of Pregnant Women in Relation to Periodontal Condition
}

\author{
Sarar Nassir Al-Najjar, B.D.S. ${ }^{1}$, Baydaa Hussein, B.D.S., M.Sc. ${ }^{2}$
}

\begin{abstract}
Background: pregnant women experienced pronounced oral changes. Saliva composition particularly the antioxidants showed significant changes among pregnant women. Aim: The aims of this study were to assess the level of salivary antioxidants (glutathione peroxidase and selenium).Additionally, periodontal healthwas assessed among a group of pregnant women in comparison with non-pregnant women. Subjects, materials and methods: The study group consisted of sixty pregnant women, they were divided into three equal groups according to trimester (20 pregnant women for each trimester), and they were selected randomly from the Maternal and Child Health Care Centers in Baghdad city, their age range was 20-25 years. In addition to 60 newly married non-pregnant women as a control group and matched with age. Collection of unstimulated salivary samples was carried out under standardized conditions. Periodontal status was evaluated using the gingival index, periodontal pocket depth. The salivary samples were analyzed to determine the level of salivary antioxidants (glutathione peroxidase and selenium). Result: The data analysis of the present study found that the level of salivary antioxidants (glutathione peroxidase and selenium) werelower among pregnant women compared to non-pregnant controls with statistically highly significant difference between them $(P<0.01)$. Regarding trimester of pregnancy, the level of salivary antioxidants (glutathione peroxidase and selenium) were the lowest in third trimester with statistically significant difference for glutathione peroxidase $(P<0.05)$ and statistically highly significant difference for selenium $(P<0.01)$. The values of gingival index and probing pocket depth were higher among pregnant women compared to non-pregnant controls with statistically highly significant difference between them $(p<0.01)$. Regarding trimester of pregnancy, the values of gingival index and probing pocket depth were the highest in the second trimester with statistically highly significant difference among three groups ( $<<0.01)$. Conclusion: The current study showed a decrease in antioxidant status increase in oxidative status saliva during pregnancy, that could affect periodontal health which was also affected by pregnancy.
\end{abstract}

Keywords: periodontal diseases pregnancy glutathione peroxidase and selenium

\section{Introduction}

Periodontal diseases are a group of conditions that cause inflammation and destruction to the supporting structures of the teeth. These chronicoral infections are characterized by the presence of a biofilm matrix thatadheres to the periodontal structures and serves as a reservoir for bacteria.Dental plaque biofilm is a complex structure of bacteria that is marked by the excretion of a protective and adhesive matrix ${ }^{(1)}$.Within this matrix are gram-negative anaerobic and microaerophilic bacteria that colonize on the tooth structures, initiate the inflammatory process, and can lead to bone loss and the migration of the junctional epithelium, resulting in periodontal pocketing and periodontal disease $^{(2)}$.

Pregnancy is a unique period during woman's life, characterized by complex physiological changes, which may adversely affect oral health ${ }^{(3)}$. During pregnancy, the most common dental problem for the mother is the periodontal disease ${ }^{(4)}$. The link between pregnancy and periodontal inflammation has been known for many years that was characterized by erythema, edema, hyperplasia, and increased bleeding ${ }^{(5)}$. On the other hand, gingival tissue physiology may be affected by hormones alteration, it become swollen, bright red in color and bleeds easily ${ }^{(6)}$.

Saliva as a minor host factor affects oral health through its physicochemical characteristics such as salivary flow rate, buffer capacity, $\mathrm{pH}$, etc ${ }^{(7)}$. One of the important defense mechanism in saliva is the antioxidant system ${ }^{(8)}$, which defined as molecules that slow or prevent or inhibit the oxidation of other (substrate) molecules ${ }^{(9)}$. The value of saliva as biological fluid for the detection of diagnostic and prognostic biomarkers have become well-established because of saliva contains locally produced as well as serum-derived markers that are useful in the diagnosis of a variety of systemic disorder ${ }^{(10)}$. Selenium behaves both as an antioxidant and anti-inflammatory agent. This is because selenium is its antioxidant role, can reduce hydrogen peroxide, lipid and phospholipids hydroperoxides, thereby dampening the propagation of free radicals and reactive oxygen species; reduce hydroperoxide intermediates in the cyclo-oxygenase and lipoxygenase pathways diminishing the production of inflammatory prostaglandins and leukotrienes. selenium with glutathione peroxidase reduces the radical-derived $\mathrm{H} 2 \mathrm{O} 2$ content thus preventing the further deterioration by the radicals, which increase the proteolytic activity.

Glutathione peroxidase (GPx) is a selenium-dependent enzyme ${ }^{(11)}$ and one of the most important enzymes for directly regulating ROS and is an important participant in antioxidant protection and detoxification ${ }^{(12)}$.As far as it is known, there were no previous Iraqi studies concerned with the assessment of the level of salivary antioxidant (selenium, GPx) and periodontal health condition among pregnant women with regard to trimester of pregnancy; therefore, it was decided to conduct this study.

\section{Materials and Methods}

The total sample for this study consisted of one hundred and twenty married women aged 20-25 years who were

\section{Volume 6 Issue 12, December 2017}




\section{International Journal of Science and Research (IJSR) \\ ISSN (Online): 2319-7064}

Index Copernicus Value (2016): 79.57 | Impact Factor (2015): 6.391

attending Maternal and Child Health Care Centers in Baghdad city. They were divided into two groups: the study group which included 60 pregnant women who further subdivided into three subgroups according to trimester (20 women for each trimester of pregnancy) and the control group which included 60 non-pregnant married nulliparous women (not being pregnant before) having a history of regular menstrual cycles (28-30 days) they were selected randomly from companions of pregnant women; those women were matched with age. All women should have at least twenty teeth to be examined. women with systemic diseases that may affect oral health, or those who had medications which may affect periodontal health condition or had course of anti-inflammatory and antibiotic drugs during the last month before examination and those who were smoking, obese, used dietary supplement (vitamins, folic acid) or had a history of abortion, history of polycystic ovaries, hormonal disturbances, used of contraceptive, nonpregnant women on mensural cycle, wearing fixed or removable dental prostheses were excluded from this study. All participants signed informed consents, and the protocol of the study had been approved by ethical committee.

The collection of unstimulated salivary sample was performed under standardized condition following the instructions cited by Navazesh and Kumar ${ }^{(13)}$. Gingival index (GI) ${ }^{(14)}$ and probing pocket depth ${ }^{(15)}$ were used for recording the periodontal health condition. The salivary samples were taken to the laboratory for biochemical analysis at the Poisoning Consultation Center/Gazi AlHariry hospital.The level of salivary antioxidant (glutathione peroxidase) was determined calorimetrically using the spectrophotometer (Cecil CE 1011, UK). Salivary selenium level was measured by spectrophotometer system using atomic absorption spectrometer nov 350AA model (Analytikjena, Germany, 2012). Mode of action of system was absorption. This measurement was performed in Ibn Sina Labs, Ministry of Industry \& minerals. Data analysis was conducted by application of SPSS program (SPSS version 21). Wilcoxon-sum rank test is non parametric test was used to determine whether two independent samples were selected from populations having the same distribution. Spearman correlation is non parametric test was used to evaluate the monotonic relationship between two nonparametric quantitative or ordinal variables. P-values less than 0.05 were recorded as statistically significant.

\section{Results}

Table (1) demonstrates the median and mean rank values of gingival index and the probing pocket depth for the study and control groups. It was found that GI and PPD were higher in the study group than that for the control group withstatistically highly significant difference between them $(\mathrm{p}<0.01)$.

According to trimester, Table (2) shows that the highest value for GI and PPD were the highest in the 2 nd trimester with statistically highly significant difference among three groups $(\mathrm{p}<0.01)$.

Table (3) shows the values of salivary antioxidants (Selenium, GPx) among the study and control groups. It was found that the salivary antioxidants (Selenium, GPx) were lower in the study group than that of the control group with statistically highly significant difference between them $(\mathrm{P}<0.01)$.

Regarding trimester of pregnancy, Table (4) shows the values of salivary antioxidants (Selenium, GPx) among pregnant women according to gestation age.It was found that the salivary antioxidants (Selenium, GPx) were lowest in the 3rd trimester with statistically significant difference for GPx $(\mathrm{P}<0.05)$ and statistically highly significant difference for selenium $(\mathrm{P}<0.01)$.

Table (5) demonstrates spearman correlation coefficient between GI with salivary antioxidants (Selenium, GPx) among study and control group. Negative correlations were found between GI and salivary selenium in both study and control groups with statistically significant difference $(\mathrm{P}<0.05)$.

Regarding pregnancy trimester, Table (6) shows negative correlations between salivary selenium and GI in the $1^{\text {st }}$ and $3^{\text {rd }}$ trimester. However, all correlations were statistically not significant $(\mathrm{P}>0.05)$.

Table (7) demonstrates the correlation between PPD and salivary antioxidants among the study group and control group. It was found that the correlations between PPD and salivary antioxidant (selenium) was negative with statistically no significant difference $(\mathrm{P}<0.05)$.

Regarding pregnancy trimester, Table (8) demonstrates spearman correlation coefficient between PPD and salivary antioxidants among trimesters of pregnancy. Negative correlation was found between salivary selenium and PPD in $2^{\text {nd }}$ trimester with statistically no significant difference $(\mathrm{P}<0.05)$.

\section{Discussion}

Pregnancy is a physiological state accompanied by a highenergy demand and an increased oxygen requirement. Augmented levels of oxidative stress would be expected because of the increased intake andutilization of oxygen ${ }^{(16)}$ Evidence of increased oxidative stress in normal pregnancy in comparison with non-pregnant controls was estimated by measuring enzymatic antioxidants (Glutathione peroxidase and selenium).Selenium is an essential antioxidant trace mineral for the human body. It is a component of selenoproteins such as the antioxidant enzyme glutathione peroxidase (GPx), which protects human tissue from damage by hydrogen peroxide, lipid peroxides and free radicals ${ }^{(17)}$. Geographical location, soil content, intake of selenium in diet and its bioavailability significantly affect selenium status ${ }^{(18)}$. Saliva is considered as a mirror of the human body's health that reflects the normal internal characteristics and disease as most compounds found in blood are also present in saliva ${ }^{(19,20)}$.

The result of current study showed that the level of salivary selenium was lower among pregnant women than that of non-pregnant women.Several reasons may be responsible for the lower levels found in this study. Active transfer of

\section{Volume 6 Issue 12, December 2017}




\section{International Journal of Science and Research (IJSR) \\ ISSN (Online): 2319-7064}

Index Copernicus Value (2016): 79.57 | Impact Factor (2015): 6.391

selenium from maternal blood to the tissues of the developing fetus had been advocated ${ }^{(21)}$. Indeed, hemodilution due to increased plasma volume in pregnancy further depletes selenium concentration. Additionally, inadequate intake and storage in the maternal tissues and increased demand by the growing fetus invariably leads to low maternal levels during pregnancy ${ }^{(22)}$, furthermore, pregnancy is a stressful condition and there is increased oxidative stress $\mathbf{( 2 3 , 2 4 )}$ and selenium is an essential antioxidant trace mineral ${ }^{(17)}$, thus, it is invaluable in the protection of the tissues against oxidative stress and this may give another explanation for the reduction in its level in comparison with the control. Regarding pregnancy trimester, the lowest level of salivary selenium was in $3^{\text {rd }}$ trimester. The level decreased as gestation progressed, this may be due to its utilization as defense mechanisms against reactive oxygen species/free radical during the oxidative stress of pregnancy (25), additional factors include hemodilution of pregnancy, when plasma volume may increase by $40-50 \%{ }^{(26,27)}$, and active transport of selenium from mother to fetus ${ }^{(28)}$. Furthermore, normal physiologic adjustments to pregnancy and response to hormonal changes may also contribute to the decline in selenium during pregnancy ${ }^{(29,17)}$.

Glutathione peroxidase is a selenium-dependent enzyme, reduces hydrogen peroxide and organic peroxides and leads to the oxidation of glutathione (GSH). Along with the other antioxidant enzymes, GPx protects cells and tissues from damage caused by reactive oxygen species by helping to maintain balance between pro-oxidant and antioxidant forces $(30,31)$

In the present study, salivary glutathione peroxidase level was lower among the pregnant women group as compared to the control group and the same result reported by ${ }^{(32)}$. The lower level of salivary GPx in comparison with controls could be due to either increase consumption and/or decrease production of antioxidants and the increased consumption of antioxidants is due to increased scavenging of oxidants among pregnant women ${ }^{(33)}$.

Regarding trimester, the result of the current study revealed that there was a progressive fall in activity of GPx as pregnancy advanced and as selenium, GPx is important antioxidant and it is utilized in defense mechanism against ROS/free radical during pregnancy ${ }^{(34)}$ and thus its level depleted in $3^{\text {rd }}$ trimester, since pregnancy is a condition that favors oxidative stress. ${ }^{(35)}$.

The result of the present study showed an increase in gingival index value among pregnant women in comparison to the controls and this could be attributed to the followings:

1) Poor oral hygiene as indicated by the higher plaque accumulation among the pregnant women than nonpregnant women. It was proven that dental plaque is the main etiological factor of gingivitis ${ }^{(36)}$. It was obvious that pregnant women had poor oral hygiene and this may be explained by that pregnancy is stressful condition and associated with many physiological and psychological events that sequential lead to more self-neglect ${ }^{(37)}$.

2) Lower antioxidants level which indicated by a decrease in salivary (selenium, glutathione peroxidase) among pregnant women as compared to the controls since antioxidants enhance periodontal health by providing protection against ROS-induced damage of periodontal tissues ${ }^{(38)}$ and this is supported by the inverse correlation between salivary selenium and gingivitis among pregnant women in present study.

Furthermore, another explanation for higher level of gingival index among pregnant women as compared to control could be the hormonal changes during pregnancy, the elevated levels of estrogen and progesterone in pregnancy could alter the connective tissue ground substance by increase fluidity and affect degree of keratinization of gingival epithelium, the decrease in the keratinization of gingiva, together with an increase in epithelial glycogen, result in decreased effectiveness of the epithelial barrier in pregnant women and make gingival more sensitive to injury ${ }^{(39)}$. When the female sex hormones act at high concentrations for prolonged periods, an increase in the permeability within the periodontal vascular system could occur. Additionally, it wasreported that there was a significant connection between pregnancy-related vomiting and increased gingival inflammation and it was speculated that the main reason for this was impaired capability for proper brushing ${ }^{(40)}$.

Regarding the trimester of pregnancy, the highest value was found in $2^{\text {nd }}$ and $3^{\text {rd }}$ trimester, however, statistically no significant difference was found between $2^{\text {nd }}$ and $3^{\text {rd }}$ trimester. The same result was also reported by previous studies $^{(41,42)}$. A possible explanation of this result is that the difference in gingival inflammation is related to the time of pregnancy. According to many studies, it was found that the severity of gingival inflammation starts to increase from the 2 nd month and rising later on ${ }^{(43)}$. This is supported by the result of this study in which a significant difference between $1^{\text {st }}$ and $2^{\text {nd }}$ trimester regarding gingival index the followings may explain the reason for the increased gingivitis with advancing pregnancy especially in $2^{\text {nd }}$ trimester.

1) Poor oral hygiene as pregnancy advanced. During the first trimester of pregnancy the nausea and vomiting during the first week may be attributed to increase plaque and most the pregnant women reported that tooth brushing was nearly impossible, especially in premolar and molar areas because of the pregnancy-related nausea (44), while during 3rd trimester pregnant women may become anxious, restless and exhausted.

2) In addition to poor oral hygiene, there can be other committing factors that vigor the gingival inflammation during pregnancy. This could be attributed to that estradiol and progesterone had higher concentrations during pregnancy with peak plasma level during the 2nd and 3rd trimesters and that these concentrations were positively correlated with the level of gingival inflammation during pregnancy ${ }^{(45)}$. As mention previously, the effect of these two hormones on the gingival health estrogen, increase cellular proliferation in blood vessels; decreases keratinization, while increasing epithelial glycogen; anabolic effect of estradiol in maintaining bone mass in periodontal region ${ }^{(46)}$. While progesterone, increase vascular dilation, thus increases permeability (results in edema and accumulation of inflammatory cells); increases proliferation of newly formed capillaries in gingival tissues (it increased

\section{Volume 6 Issue 12, December 2017}




\section{International Journal of Science and Research (IJSR) \\ ISSN (Online): 2319-7064}

Index Copernicus Value (2016): 79.57 | Impact Factor (2015): 6.391

bleeding tendency); alters rate and pattern of collagen production (it reduced repair and maintenance by inhibition of fibroblast); increase metabolic breakdown of folate (a deficiency can inhibit tissue repair) ${ }^{(47)}$. Also with increasing sex hormones level the defense mechanisms necessary for the maintenance of good oral health are compromised and certain bacteria harmful to oral environment are allowed to increase (overgrowth of $P$. intermedia is associated with increase gingival inflammation in 2nd trimester and increase in $P$. gingivitis and $\mathrm{T}$. forsythia correlate with increase in gingival bleeding) ${ }^{(48,49)}$.

3) Lower antioxidant protection as indicated by negative correlation between gingival index and salivary antioxidants (selenium) in $3^{\text {rd }}$ trimester in this current study and it was consistent with other ${ }^{(50)}$. The antioxidants are utilized to maintain the balance and so the level of antioxidant decreases. it was reported that reduced antioxidant activities in saliva reflecting increased oxygen radical production or activity during periodontal inflammation ${ }^{(51)}$. Furthermore, antioxidants may be depleted probably because of overwhelming free radical's generation and elevated levels of ROS ${ }^{(52)}$, and as recently has been hypothesized that pregnancy is proinflammatory condition associated with an inflammatory response characterized by leukocyte activation $^{(53,54)}$.

In the current study the majority of women were with clinical pocket depth less than $4 \mathrm{~mm}$. On the other hand, clinical pocket depth equal to $4 \mathrm{~mm}$ was found only among pregnant women. This could be explained by that in the current study women examined were young since age is considered as one of the risk factors or indicators of periodontal disease ${ }^{(55)}$.

Periodontitis represents pocket depth that is greater than $4 \mathrm{~mm}$, while false pocket if present usually do not exceed $4 \mathrm{~mm}{ }^{(56)}$. This means that all of the pregnant women with pocket depth equal to $4 \mathrm{~mm}$ had false pocket. This indicates that gingival alterations are more marked during pregnancy and none of them periodontitis.

Regarding trimester, majority of women with PPD equal $4 \mathrm{~mm}$ were in the 2 nd trimester followed by the $3 \mathrm{rd}$ one, this result was somewhat consistent with others ${ }^{(56,45,57,58)}$. This could be related to severe gingival inflammation with the associated gingival enlargement during pregnancy (especially in the second and third trimesters) which causes an increase in the depth of the gingival sulcus rather than periodontal destruction (false pocket).

\section{References}

[1] Thomas JG, Nakaishi LA. Managing the complexity of a dynamic biofilm. J Am Dent Assoc. 2006;137(supp):10S-15S.

[2] Slade GD, Ghezzi EM, Heiss G, Beck JD, Riche E, OffenbacherS. Relationship between periodontal disease and Creactiveprotein among adults in the atherosclerosis risk incommunities' study. Arch Intern Med. 2003; 163(10):1172-9.
[3] Jolene Berthness, katrina Holt. Oral Health Care During Pregnancy: A Resource Guide. National Maternal and Child Oral Health Resource Center. Georgetown University. 2012: P (7).

[4] Laine MA. Effect of pregnancy on periodontal and dental health. ActaOdontolScand.2002;60:257-64.

[5] Carranza. Clinical periodontology by Newman M., Taki H., Carranza F.Part 3, Saunder Elsevier 9th ed. 2002: 164-150.

[6] Kornman KS, Loesche WJ. The subgingival microbial flora during pregnancy. J Periodont Res. 2008: (5): 1232.

[7] Tulunoglu O, De Mirtas S, TuLunoglu I. Total antioxidant levels of saliva in children related to caries, age and gender. Int J Paediatr Dent. 2006; 16 (3): 18691.

[8] Gorelik S, Kohen R, Ligumsky M, Kanner J. Saliva plays a dual role in oxidation process in stomach medium. Arch BiochemBiophys. 2007; 458(2): 236243.

[9] Mohammad M, Tahir Soomro M, Tariq M. Poster Presentation in Conference on, "Free Radicals in Biosystem”, Kuwait J. Mol.Biotechnol 2007; (3): 18-21.

[10] Kaufman E, Lamster I. Analysis of saliva for periodontal diagnosis: a review. J ClinPeriodontol, 2000; 27, 453-465.

[11] Denisov ET, Afanas'ev IB. Oxidation and antioxidants in organic chemistry and biology. Taylor and Francis, 2005.

[12] Muthukumar, K. et al. Glutathione peroxidase3 of Saccharomyces cerevisiaeprotects phospholipids during cadmium-induced oxidative stress. Antonie Van Leeuwenhoek. 2011; 99, 761-771.

[13] Navazesh M, Kumar S, Measuring salivary Flow: Challenges and opportunities. JAPA 2008; 139(2): 355405.

[14] Sillness J, Loe H, Periodental disease in pregnancy II.ActaOdontolScand 1964; 24: 747-59.

[15] Ramfjord SP. Indices for prevalence and incidence of periodontal disease. J Periodontol 1959; 30: 51-9.

[16] Patil SB, Kodliwadmath MV, Kodliwadmath SM. Study of oxidative stress and enzymatic antioxidants in normal pregnancy. Indian Journal of Clinical Biochemistry. 2007 Mar 1;22(1):135-7.

[17] Burk RF. Selenium, an antioxidant. NutriClin Care 2000; 5(2):75-9.

[18] Wasowicz, W., Gromadzinska, J., Rydzynski, K. and Tomczak, J., 2003. Selenium status of low-selenium area residents: Polish experience. Toxicology Letters, 137(1), pp.95-101.

[19] Lee, JM. Garon, E. \&Wong DT. "Salivary diagnostics". OrthodCranioFac Res. 2009; 12: 206- 211.

[20] Chiappin, S. Antonelli, G. Gatti, R. \& De Palo, EF. Saliva specimen: a new laboratory tool for diagnostic and basic investigation. Clin Chin Acta. 2007; 383: 30 40.

[21] Olife IC, Okaka AN, Dioka CE, Meludu SC, Orisakwe OE. Iodine status and the effect of soil erosion on trace elements in Nanka and Oba towns of Anambra State, Nigeria. Annali di chimica. 2007 Aug 1;97(9):895-903.

[22] Nwagha UI, Ogbodo SO, Nwogu-Ikojo EE, Ibegbu DM, Ejezie FE, Nwagha TU, Dim CC. Copper and selenium status of healthy pregnant women in Enugu, 


\section{International Journal of Science and Research (IJSR) \\ ISSN (Online): 2319-7064}

Index Copernicus Value (2016): 79.57 | Impact Factor (2015): 6.391

southeastern Nigeria. Nigerian journal of clinical practice. 2011;14(4):408-12.

[23] Walsh, S.W., 1994. Lipid peroxidation in pregnancy. Hypertension in pregnancy, 13(1), pp.1-32.

[24] Qanungo, S. and Mukherjea, M., 2000. Ontogenic profile of some antioxidants and lipid peroxidation in human placental and fetal tissues. Molecular and cellular biochemistry, 215(1), pp.11-19.

[25] Ejezie FE, Onwusi EA, Nwagha UI. Some biochemical markers of oxidative stress in pregnant Nigerian women. Tropical Journal of Obstetrics and Gynaecology. 2004;21(2):122-4.

[26] Tamura T, Goldenberg RL, Johnston KE, DuBard M. Maternal plasma zinc concentrations and pregnancy outcome. The American journal of clinical nutrition. 2000 Jan 1;71(1):109-13.

[27] Akande AA, Okesina AB, Godzama AA. Maternal serum total protein and albumin levels during pregnancy. Savannah Med J 2001; 4: 30-1.

[28] Nandakumaran M, Dashti HM, Surname F. Maternalfetal transport kinetics of copper, selenium, magnesium and iron in perfused human placental lobule: in vitro study. Molecular and cellular biochemistry. 2002 Feb 1;231(1):9-14.

[29] Reyes H, Báez ME, González MC, Hernández I, Palma J, Ribalta J, Sandoval L, Zapata R. Selenium, zinc and copper plasma levels in intrahepatic cholestasis of pregnancy, in normal pregnancies and in healthy individuals, in Chile. Journal of hepatology. 2000 Apr 30;32(4):542-9.

[30] Knapen, M. F. C. M. The glutathione/glutathionerelated enzyme system in reproduction. Eur J ObstetGynecolReprod Biol. 2000 91:127-129.

[31] Gitto, E., Reiter, R.J., Karbownik, M., Tan, D.X., Gitto, P., Barberi, S. and Barberi, I. Causes of oxidative stress in the pre-and perinatal period. Neonatology. 2002; 81(3), pp.146-157.

[32] Gümüş P, Emingil G, Öztürk VÖ, Belibasakis GN, Bostanci N. Oxidative stress markers in saliva and periodontal disease status: modulation during pregnancy and postpartum. BMC infectious diseases. 2015 Dec $1 ; 15(1): 261$.

[33] Usha Rani D, Arifuddin MS, Hazari MA, Haragopal R, Reddy BR. Levels of Upper Limit of Oxidative Stress Markers During Normal Pregnancy and PreEclampsia.JMSCR. 2015 Jan; 03(01), pp. 3674-3682.

[34] Matés JM. Effects of antioxidant enzymes in the molecular control of reactive oxygen species toxicology. Toxicology 2000; 153: 83-104.

[35] Casanueva E, Viteri FE. Iron and oxidative stress in pregnancy. The Journal of nutrition. 2003 May 1;133(5):1700S-8S.

[36] Peter J. Robinson, Michael Schmerman. Influence of Pregnancy on the Oral Cavity. lob. libr. women's med., (ISSN: $1756-2228) \quad$ 2015; 10.3843/GLOWM.10105.

[37] Takahashi N and Nyvad B. Caries ecology revisited: microbial dynamics and the caries process. J Caries Res 2008; 42: 409-18.

[38] Chapple ILC. Role of free radicals and antioxidants in the pathogenesis of the inflammatory periodontal diseases. J ClinPatholMolPathol 1996; 49: 247-55.
[39] Jensen J., Lili jmack W., Blookquist C.: The effect of sex hormones on subgingival plaque J. Periodonal .1981; 52(10): 599-602.

[40] Taani, D. Q., Habashneh, R., Hammad, M.M. \&Batieha, A. The periodontal status among pregnant women $\&$ its relationship with socio-demographic \& clinical variables. J Oral Rehabilitation. 2003; 30, 440-445.

[41] Mirza, KB. Al- Saidy, AH. And Mohammad CM. The Prevalence and Severity of Periodontal Disease in Different Stages of Pregnancy and in Women Taking Oral (Contraceptive Pills) in Sulaimani City, Kurdistan Region, Iraq. Diyala Journal of Medicine. 2013; 4 (1).

[42] Mutlak NQ. Salivary physico- chemical properties in relation to oral health status among a group of pregnant women. Master Thesis, College of Dentistry, University of Baghdad.2016

[43] Cohen DW, Friedman L, Shapiro J, Kyle GC. A longitudinal investigation of the periodontal changes during pregnancy. Journal of periodontology. 1969 Oct;40(10):563-70.

[44] Gürsoy M, Pajukanta R, Sorsa T, Könönen E. Clinical changes in periodontium during pregnancy and post-partum. Journal of Clinical Periodontology. 2008 Jul 1;35(7):576-83.

[45] Salameh RM. The periodontal status during pregnancy and intake of contraceptives. M. Sc. Thesis, College of Dentistry, University of Baghdad.2000.

[46] Lindhe J.Karring T,\& Lang P. Clinical periodontology and implant dentistry. 4th ed. Oxford, University press.2003.

[47] Corgel JO. Periodontal therapy in the female patient (puberty, menses, pregnancy, and menopause). In: Clinical periodontology by NEWMAN, M. TAKI, H. \& CARRANZA, F. Saunders an imprint of Elsevier. 9th. 2002.

[48] Preckshot J. Women's Oral Health: Is There a Hormonal Link? International journal of pharmaceutical compounding. 2004;8(1):10.

[49] Adriaens LM, Alessandri R, Sporri S, Lang NP \&Persson GR. Does pregnancy have an impact on the subgingival microbiota? Journal of Periodontology. 2009; 80, 72-81.

[50] Trivedi S. and Lal N. Antioxidant enzymes in periodontitis. Journal of oral biology and craniofacial research. 2017; 7(1), pp.54-57.

[51] CanakciCF, Cicek Y, Yildirim A, Sezer U and Canakci V. Increased levels of 8-hydroxydeoxyguanosine and malondialdehyde and its relationship with antioxidant enzymes in saliva of periodontitis patients. European journal of dentistry. 2009; 3(2), p.100.

[52] Halliwell B, Gutteridge J. In free radicals in biology and medicine. 3rd ed., Oxford University Press, Oxford, 2007.

[53]Faas MM, Moes H, de Vos P. Monocyte cytokine production during pregnancy. J LeukocBiol 2004; 75:153-4.

[54] Belo L, Santos-Silva A, Rocha S, et al. Fluctuations in C-reactive protein concentration and neutrophil activation during normal human pregnancy. Eur J ObstetGynecolReprodBiol 2005; 123:46-51.

[55] Khader, Y.S., Rice, J.C. and Lefante, J.J., 2003. Factors associated with periodontal diseases in a dental teaching 


\section{International Journal of Science and Research (IJSR) \\ ISSN (Online): 2319-7064 \\ Index Copernicus Value (2016): 79.57 | Impact Factor (2015): 6.391}

clinic population in northern Jordan. Journal of periodontology, 74(11), pp.1610-1617.

[56] Brown, L.J., Oliver, R.C. and Löe, H., 1989. Periodontal diseases in the US in 1981: prevalence, severity, extent, and role in tooth mortality. Journal of periodontology, 60(7), pp.363-370.

[57] Miyazaki, H., Yamashita, Y., Shirahama, R., Goto-Kimura, K., Shimada, N., Sogame, A. and Takehara, T., 1991. Periodontal condition of pregnant women assessed by CPITN. Journal of clinical periodontology, 18(10), pp.751-754.
[58] Yalcin, F., Eskinazi, E., Soydinc, M., Basegmez, C., Issever, H., Isik, G., Berber, L., Has, R., Sabuncu, H. and Onan, U., 2002. The effect of sociocultural status on periodontal conditions in pregnancy. Journal of periodontology, 73(2), pp.178-182.

[59] YAS, B. 2004. Evaluation of oral health status, treatment needs knowledge, attitude and behavior of pregnant woman in Baghdad governorate. M.Sc. Thesis submitted to the Collage of Dentistry, University of Baghdad.

Table 1: Gingival index and probing pocket depth (median, mean rank) among the study and control groups

\begin{tabular}{|c|c|c|c|c|c|c|c|c|c|}
\hline & \multicolumn{2}{|c|}{ 1st trimester } & \multicolumn{2}{|c|}{ 2nd trimester } & \multicolumn{2}{c|}{ 3rd trimester } & \multicolumn{3}{c|}{ Kruskal-wallis } \\
\cline { 2 - 10 } Variable & Median & Mean rank & Median & Mean rank & Median & Mean rank & Chi-square & df & Sig. \\
\hline Selenium $(\mathrm{mg} / \mathrm{ml})$ & 3.36 & 26.30 & 5.05 & 41.08 & 3.31 & 24.13 & 11.185 & 2 & $0.004 * *$ \\
\hline Glutathione peroxidase $(\mathrm{U} / \mathrm{ml})$ & 0.41 & 37.38 & 0.39 & 31.95 & 0.30 & 22.18 & 7.840 & $0.020^{*}$ \\
\hline
\end{tabular}

** Highly significant $(\mathrm{P}<0.01)$

Table 2: Gingival index and probing pocket depth (median, mean rank) and statistical difference among pregnant women according to gestation age

\begin{tabular}{|c|c|c|c|c|c|c|c|}
\hline \multirow{2}{*}{ Variable } & \multicolumn{4}{|c|}{ Groups } & \multicolumn{3}{c|}{ Wilcoxon sum rank test } \\
\cline { 2 - 8 } & \multicolumn{2}{|c|}{ Pregnant } & \multicolumn{2}{c|}{ Non-pregnant } & \multicolumn{3}{|c|}{} \\
\cline { 2 - 8 } & Median & Mean rank & Median & Mean rank & $\mathrm{W}$ & $\mathrm{Z}$ & P-value \\
\hline Selenium(mg/ml) & 4.10 & 47.65 & 5.55 & 73.35 & 2859 & 4.047 & $0.000^{* *}$ \\
\hline Glutathione peroxidase $(\mathrm{U} / \mathrm{ml})$ & 0.39 & 38.53 & 0.59 & 82.47 & 2312 & 6.925 & $0.000^{* *}$ \\
\hline
\end{tabular}

** Highly significant $(\mathrm{P}<0.01)$

* significant $(\mathrm{P}<0.05)$

Table 3: Salivary antioxidants (glutathione peroxidase, Selenium) (median, mean rank) and statistical difference between study and control group

\begin{tabular}{|c|c|c|c|c|c|c|c|}
\hline \multirow{2}{*}{ Variables } & \multicolumn{4}{|c|}{ Groups } & \multicolumn{3}{c|}{ Wilcoxon sum rank test } \\
\cline { 2 - 7 } & \multicolumn{2}{|c|}{ Pregnant } & \multicolumn{2}{c|}{ Non-pregnant } & \multicolumn{3}{c|}{ P-value } \\
\cline { 2 - 8 } & Median & Mean Rank & Median & Mean Rank & W & Z & P-von \\
\hline GI & 1.40 & 90.50 & 0.20 & 30.50 & $\mathbf{1 8 3 0}$ & 9.573 & $0.000^{* *}$ \\
\hline PPD & 0.00 & 67.00 & 0.00 & 54.00 & $\mathbf{3 2 4 0}$ & 3.802 & $0.000^{* *}$ \\
\hline
\end{tabular}

** Highly significant $(\mathrm{P}<0.01)$.

Table 4: Salivary antioxidants (Selenium, Glutathione peroxidase) (median, mean rank) and statistical difference among pregnant women according to gestation age

\begin{tabular}{|l|c|c|c|c|c|}
\hline \multirow{2}{*}{ Variables } & \multicolumn{4}{|c|}{ Group } \\
\cline { 2 - 5 } & \multicolumn{2}{|c|}{ Study } & \multicolumn{2}{c|}{ Control } \\
\cline { 2 - 5 } & \multicolumn{2}{|c|}{ GI } & \multicolumn{2}{c|}{ GI } \\
\cline { 2 - 6 } & $\mathrm{r}$ & $\mathrm{P}$ & $\mathrm{r}$ & $\mathrm{p}$ \\
\hline Selenium $(\mathrm{mg} / \mathrm{ml})$ & -0.124 & 0.344 & -0.263 & $0.042 *$ \\
\hline Glutathione peroxidase $(\mathrm{U} / \mathrm{ml})$ & 0.042 & 0.750 & 0.045 & 0.730 \\
\hline
\end{tabular}

** Highly significant $(\mathrm{P}<0.01)$

Table 5: Correlation coefficient between gingival index and salivary antioxidant (selenium, glutathione peroxidase) among study and control group

\begin{tabular}{|c|c|c|c|c|c|c|}
\hline \multirow{4}{*}{ Variables } & \multicolumn{6}{|c|}{ Pregnancy trimesters } \\
\hline & \multirow{2}{*}{\multicolumn{2}{|c|}{$\frac{1^{\text {st }} \text { trimester }}{\text { GI }}$}} & \multirow{3}{*}{\begin{tabular}{|c} 
nd \\
$\mathrm{GI}$ \\
$\mathrm{r}$
\end{tabular}} & \multirow{2}{*}{\multicolumn{2}{|c|}{$\begin{array}{l}{ }^{\text {rd }} \text { trimester } \\
\text { GI }\end{array}$}} & \multirow[b]{3}{*}{$\mathrm{p}$} \\
\hline & & & & & & \\
\hline & $\mathrm{r}$ & $\mathrm{p}$ & & $\mathrm{p}$ & $\mathrm{r}$ & \\
\hline Selenium $(\mathrm{mg} / \mathrm{ml})$ & 0.359 & 0.121 & 0.229 & .332 & 0.083 & .728 \\
\hline $\mathrm{GPx}(\mathrm{U} / \mathrm{ml})$ & 0.371 & 0.107 & 0.226 & .338 & 1.327 & .159 \\
\hline
\end{tabular}

Table 7: Correlation coefficient between probing pocket depth and salivary antioxidant (selenium, glutathione peroxidase) among study and control group

\begin{tabular}{|c|c|c|}
\hline \multirow{2}{*}{ Variable } & \multicolumn{2}{|c|}{ Group } \\
\cline { 2 - 3 } & \multicolumn{2}{|c|}{ PPD } \\
\cline { 2 - 3 } & $\mathrm{r}$ & $\mathrm{p}$ \\
\hline Selenium(mg/ml) & -0.112 & 0.393 \\
\hline glutathione peroxidase $(\mathrm{U} / \mathrm{ml})$ & 0.086 & 0.516 \\
\hline
\end{tabular}

\section{Volume 6 Issue 12, December 2017} www.ijsr.net 


\section{International Journal of Science and Research (IJSR) \\ ISSN (Online): 2319-7064}

Index Copernicus Value (2016): 79.57 | Impact Factor (2015): 6.391

Table (8): Correlation coefficient between probing pocket depth and salivary antioxidant (selenium, glutathione peroxidase) among pregnant women according to gestation age

*Significant $(\mathrm{P}>0.05)$

\begin{tabular}{|c|c|c|c|c|}
\hline \multirow{2}{*}{ Variable } & \multicolumn{4}{|c|}{ Pregnancy trimesters } \\
\cline { 2 - 5 } & \multicolumn{2}{|c|}{$2^{\text {nd }}$ trimester } & \multicolumn{2}{c|}{$3^{\text {rd }}$ trimester } \\
\cline { 2 - 5 } & \multicolumn{2}{|c|}{$\mathrm{PPD}$} & \multicolumn{2}{c|}{$\mathrm{PPD}$} \\
\cline { 2 - 5 } & $\mathrm{r}$ & $\mathrm{p}$ & $\mathrm{r}$ & $\mathrm{p}$ \\
\hline Selenium $(\mathrm{mg} / \mathrm{ml})$ & -0.195 & 0.409 & 0.041 & 0.862 \\
\hline $\begin{array}{c}\text { glutathione } \\
\text { peroxidase }(\mathrm{U} / \mathrm{ml})\end{array}$ & 0.180 & 0.447 & 0.171 & 0.471 \\
\hline
\end{tabular}

Volume 6 Issue 12, December 2017

www.ijsr.net

Licensed Under Creative Commons Attribution CC BY 